\title{
"TINGA TEU POVO TE AMA": ESTUDO ANTROPOLÓGICO JUNTO AOS MORADORES DO BAIRRO RESTINGA EM PORTO ALEGRE (RS).
}

\author{
Vanessa Zamboni \\ Cornelia Eckert (Orientação)
}

\begin{abstract}
...É necessário ver como cada um, em qualquer idade, nas menores coisas, como nas maiores provações procura um território para si, suporta ou carrega desterritorializações, e se territorializa quase sobre qualquer coisa, lembrança, fetiche, sonho.

(Deleuze e Guattari, O que é filosofia?1992:69).
\end{abstract}

\section{Introdução}

Esta monografia resulta de um exercício etnográfico sobre a temática do viver urbano no cotidiano de um bairro em Porto Alegre/RS. Trata da experiência dos habitantes da cidade frente à dinâmica urbana que envolve processos de desenraizamento em suas trajetórias familiares e construção dos laços de pertença, fenômenos estes envolvidos na formação e proliferação de novos bairros.

A partir de uma etnografia realizada no Bairro Restinga em Porto Alegre, no período de Janeiro de 2005 a Junho de 2006 tive como objetivo de investigação, conhecer quem são estes moradores, ou seja, de onde eles vêm? Do campo ou da cidade? Existem projetos que orientam suas trajetórias? Como é seu cotidiano nestes novos bairros? Quais as referências e os símbolos mais representativos de seu ethos cultural?

A pesquisa surgiu de um exercício etnográfico, inicialmente desenvolvido no âmbito do Projeto Banco de Imagens e Efeitos Visuais, do Laboratório de Antropologia Social/PPGAS/UFRGS, sob orientação da Prof. Dra. Cornelia Eckert e da Prof. Dra. Ana Luiza Carvalho da Rocha. Atualmente, conta com a orientação da Prof. Dra.Cornelia Eckert. O tema é vinculado ao Projeto Integrado de Pesquisa Estudo Antropológico de Itinerários Urbanos, Memória Coletiva e Formas de Sociabilidade no Meio Urbano Contemporâneo (Projeto Integrado CNPq). Neste projeto, atuando como bolsistas de Iniciação Científica CNPq, somos estimulados a adotar um espaço da cidade com vistas à investigação e realização de um exercício etnográfico. A escolha pelo bairro Restinga se deu em função de 
ser um bairro periférico, possuidor de possuir uma especificidade étnica (por contar com grande número de moradores afro-descendentes) tendo, em relação à cidade, uma história antiga em relação à trajetória de seus moradores e uma história, mais recente, ligada à atual ocupação.

O objetivo do presente estudo é desenvolver uma pesquisa antropológica sobre a trajetória dos habitantes do bairro tratando de aspectos de sua memória e identidade, relacionadas com sua vida cotidiana no bairro da cidade de Porto Alegre.

Leva-se assim em consideração a diversidade das trajetórias sociais, dos processos migratórios e das histórias familiares singulares.

O bairro Restinga, na zona sul, é um dos bairros mais populosos da capital, tendo aproximadamente 72 mil habitantes (PMPA, 2002). Tem um histórico de ocupação recente e peculiar, com início na década de 60 e intensificação nos anos 70.

Esse processo foi promovido pelo poder público que, com o aumento da população de baixa renda que residia em vilas próximas ao centro, tais como Ilhota ${ }^{1}$, Dona Theodora e Marítimos, alocou essa população. Assim, utilizou slogans como "Remover para Promover" transferindo alguns destes habitantes para a Restinga, um local a $22 \mathrm{~km}$ distante do centro da cidade.

Nas primeiras idas ao campo, encontrei um bairro populoso, com moradores dispostos a se "separar" de Porto Alegre pois, segundo eles, o bairro Restinga é uma cidade dentro da própria cidade. Outra característica que despertou atenção foi o fato de ser um bairro essencialmente negro, ou seja, com uma grande quantidade de afro-descendentes.

A percepção de seu tamanho e população também foi variada, alguns me relatavam que havia 150mil outros 500 mil habitantes, dando uma noção de um bairro muito populoso, foi quando ao consultar os dados da prefeitura (2002) verifiquei que o número oficial de habitantes é de 50 mil, contando com mais 24 mil moradores irregulares.

Um bairro que além de muitas vezes ser considerado como uma cidade a parte, ora dividido, separado por "duas Restingas", a Nova e a Velha. Com distinções tanto em sua configuração espacial quanto no plano simbólico. No plano espacial a Restinga Nova é plana e mais urbanizada e a Velha tem o terreno mais acidentado, com morros e ruas de chão batido, tendo inúmeras vielas e focos de pequenas vilas com moradias irregulares. Já no plano simbólico onde há distinções, como os moradores da Velha são vistos como mais antigos, ou 
com condições sócio-econômicas diferenciadas, sendo uma população com menos recursos nesta área, por exemplo.

Nesse sentido, a perspectiva da memória coletiva, a trajetória e a identidade são elementos que se mostraram fundamentais para interpretação dos significados atribuídos a este espaço da cidade.

\section{Inserção em campo}

\section{A Chegada ao Bairro Restinga}

A inserção em campo para a realização do exercício etnográfico no bairro Restinga iniciou em Janeiro de 2005. A pesquisa de campo consistiu fundamentalmente no trabalho de observação participante e entrevistas semi-diretas. As "idas a campo" foram caracterizadas por entrevistas mais formais, onde algumas foram gravadas e outras foram realizadas de modo mais informal, sem o uso deste. A máquina fotográfica e o diário de campo também foram instrumentos utilizados na coleta de dados.

As entrevistas foram registradas em fitas cassetes e cadernos de campo, mantendo um diário de campo para narrar eventos e expressar sentimentos, impressões e idéias em uma forma mais livre e subjetiva. Será importante ressaltar que, em nenhum momento, pretendi me colocar como observadora passiva e neutra, ou ignorar os efeitos da minha presença como ator social com os meus interlocutores. Estou ciente de que as implicações de meu viés ideológico, bem como do caráter dialético das trocas e omissões de sentimentos, conhecimentos e significados, no qual o encontro pesquisado/pesquisador está embebido (Peirano, 1997).

\section{O início da Rede de informantes}

Inicialmente, contatei com um informante-chave, morador do bairro, Iosvaldir, que é doutorando em Antropologia Social na UFRGS. Eu ainda não conhecia o bairro e antes de ir até a Restinga, Iosvaldir me passou algumas informações sobre o local, a partir de uma mescla de sua experiência de morador e sua visão antropológica sobre a cidade.

Após esse primeiro contato, surgiu a Mostra de Cinema Negro, onde a primeira sessão de exibição do filme "Filhas do Vento", um filme onde só atuam atores negros, foi realizada

\footnotetext{
${ }^{1}$ Região conhecida no passado porto-alegrense por ser um dos núcleos negros da cidade.
} 
na casa de Cultura Mário Quintana e na outra semana seria exibido na Restinga, na Escola de samba Estado Maior. Fui até lá, mas não houve a exibição era à noite e eu apenas fiquei na quadra da escola onde tive contato com o zelador do local.

Iosvaldir e eu marcamos um dia para que eu fosse até a Restinga para conhecer mais amplamente o bairro. Iosvaldir fez um breve relato de alguns processos de ocupação pelas quais a Restinga passou, desde a remoção da população de classe baixa e negra de outros bairros, como a Cidade Baixa, Bom Fim e outros bairros da cidade de Porto Alegre Processo este que iniciou na década de 70, realizada pelo DEMHAB (Departamento Municipal de Habitação), órgão da Prefeitura responsável por este tipo de política pública.

Iosvaldir é morador do conjunto habitacional Monte Castelo localizado na Restinga Nova. Nessa primeira visita, fui até sua casa e conheci sua família (mulher, filha e neto). Neste mesmo dia, Iosvaldir me apresentou o bairro; inicialmente, percorremos espaços da Restinga Nova e, depois, circundamos a Restinga Velha com algumas inserções no interior desse espaço, à medida que caminhávamos Iosvaldir me apresentou algumas pessoas para que eu já tivesse contatos quando voltasse.

Uma dessas pessoas foi Lucette, uma farmacêutica de origem africana que se instalou no bairro, produzindo medicamentos homeopáticos e alternativos baseados em plantas e chás. Lucette tem um centro de terapias alternativas, como massagens, Reiki, yoga, ministrando também aulas de dança do ventre, africana e mentalização no CECORES (Centro de Comunidade da Vila Restinga).

Na segunda visita ao bairro, fui até a farmácia de Lucette onde conversamos sobre a sua atuação no bairro e sua trajetória de vida. Lucettte relatou que ministrava aulas de dança do ventre, e outras atividades em sua ONG. Como inicialmente um dos interesses da pesquisa era ter como universo moradores idosos, no momento achei que freqüentar aulas da ONG fosse uma forma de entrar em contato com essa população, assim combinei de iniciar aulas de dança do ventre, ministradas por Lucette no CECORES as quintas-feiras.

Acreditei ser uma boa possibilidade de criar uma rede e ter um dia fixo em que estaria no bairro, tanto para iniciar contatos como para observação do cotidiano dos moradores. Portanto, freqüentei estas aulas por cerca de um mês.

Havia apenas duas idosas no grupo e no decorrer do período foram feitas algumas alterações no rumo da pesquisa. Um dos motivos dessa alteração era o conteúdo ideológico da ONG e a vinculação com a mesma, era necessário ter autonomia em relação a instituições. 
Nesse período entrei em contato com o integrante de uma ONG ligada ao Movimento Negro que me indicou o nome de Coutinho me passando seu número de telefone celular e a informação de que era fotógrafo.

Em seguida liguei para Coutinho atendeu me apresentei como estudante e falei do meu interesse de pesquisar o bairro. Combinamos de nos encontrar no dia seguinte, um Sábado.

Como não nos conhecíamos Coutinho perguntou como eu era? Para que pudesse me reconhecer. Antes disso ele auto definiu-se como sendo um "negão careca". Ao me perguntar como eu era, respondi: - sou morena e antes de prosseguir na descrição Perguntou? Tu é Negra? Respondi que não. Ele então disse: - então tu é branca. Neste momento já pude perceber alguns dos códigos e fronteiras culturais do grupo que estava prestes a conviver e investigar durante o trabalho de campo. Combinamos de nos encontrar no outro dia, às duas da tarde em frente ao bar do seu Ivo, ao lado da Escola de Samba Estado Maior da Restinga.

Peguei um ônibus na Avenida João Pessoa, o que depois acabou se tornando quase que um hábito, e às $14 \mathrm{~h}$ cheguei ao bairro, avistei a escola, e antes de chegar ao prédio, havia um barzinho em uma esquina. Após uns 5 minutos, estacionou uma moto, o rapaz, tirou o capacete e disse: - Vanessa, respondi afirmativamente, aí ele ainda com a moto ligada, estendeu a mão e nela estava um capacete. Não entendi o gesto, estava muito surpresa, não esperava aquela reação, ele disse: sobe, e eu como assim? Ele simplesmente respondeu: "Ué não quer conhecer a Restinga e pessoas antigas da comunidade?" Um pouco assustada e surpresa ainda, respondi afirmativamente. Mas, nesse momento, sentimentos se misturavam, não o conheço, não conheço o bairro, e subo na moto e ele me leva para onde quiser! Fiquei com receio sim, mas eu havia me colocado naquela situação da qual me surpreendeu porque tinha a impressão de que estava perdendo o controle. Acredito ser uma metáfora da qual o trabalho de campo nos reserva em muitas situações, elaboramos mentalmente roteiros, situações, mas na interação com o outro, estamos sujeitos a embarcar ou não. Resolvi embarcar, assim, subi na moto, outro receio que tinha, havia muito tempo que não andava de moto, mas, hesitante por um lado, e instigada pelo outro, coloquei o capacete e seguimos pela ruela, em direção ao interior do bairro, era a única informação que tinha, havíamos saído da Avenida e da região central indo em direção ao interior do bairro.

Fomos até a casa de Maria Clara e Seu Ênio antigos moradores da Restinga Velha. Bem, assim iniciaram as demais entrevistas e a rede que constitui através de Coutinho que me acompanhou durante o transcorrer da pesquisa. 


\section{Rede de moradores: Quem são? Quais suas trajetórias?}

Redes sociais são campos constituídos por relações entre pessoas (Barnes, 1987). Segundo Larissa Lomnitz (1991) redes são construções abstratas que o próprio pesquisador define de acordo com o critério que lhe interesse. O que interessa ao cientista social são as formas que estas relações estão ordenadas, assim como a conduta dos indivíduos depende de sua localização neste ordenamento e de que maneira influem os próprios indivíduos nestes.

Na rede em questão, a relação que se dá entre os indivíduos é de ordem identitária, já que estes se vinculam ao bairro Restinga, em determinado período de suas trajetórias ( Velho, 1999).

As pessoas com quem tive contato são moradores que residem há pelo menos vinte anos no bairro. Abaixo seguem os personagens presentes neste estudo, pessoas com as quais convivi durante este período de um ano e meio. Freqüentando suas casas nos finais de semana, fazendo refeições, convivendo no seu espaço familiar, e realizando entrevistas. Assim, através da observação participante no cotidiano destas pessoas, participei de festas de batuque, de bailes de carnaval e do cotidiano familiar, ou mesmo participando de suas atividades ligadas a movimentos sociais como ONGs. Segundo C. Geertz, em A interpretação das culturas (Rio de Janeiro, Zahar, 1973) "fazer antropologia é analisar as formas simbólicas - palavras, imagens, instituições, comportamentos - em termos das quais os homens se representam, para si mesmos e para os outros". Para isto, tanto as narrativas dos informantes quanto as observações realizadas em campo foram considerados fundamentais.

\section{Coutinho}

Como já havia dito anteriormente o contato com Coutinho iniciou a minha inserção na atual rede de informantes, durante o período da pesquisa, além de me apresentar para os demais moradores, fui conhecendo sua trajetória de vida. Coutinho tem 44 anos, nasceu no rio de Janeiro, em Bomsucesso e trabalhava como feirante na comunidade Cidade de Deus. Mora a 20 anos na Restinga. Chegando ao bairro atuou na policia comunitária e atualmente, é policial reformado, desempenhando atividade de fotógrafo social no bairro e de alguns eventos relacionados ao carnaval e outras atividades culturais. Também participa de duas ONGs, Guardiões da Cidadania e Instituto Afro-Tinga. A primeira é ligada a fiscalização de órgãos ligados a política, como prestação de contas a comunidade, aplicação de verbas e 
recursos e a segunda propõe a criação de um local para atividades de lazer, recreação e atividades culturais contando com quadras esportivas e biblioteca e cursos profissionalizantes para os moradores da comunidade.

O fato de ser fotógrafo permite a Coutinho a inserção em diversas camadas sociais e locais do bairro. O que sem dúvida auxiliava no conhecimento de pessoas ou mesmo de locais e eventos.

A inserção em várias esferas da vida social do bairro e em vários grupos e territórios da Restinga, também contribui para a construção da rede. Salientando que ele investiu-se do papel de informante. Organizando previamente a rede de pessoas, que segundo ele, poderiam acrescentar informações valiosas ao trabalho. Selecionando assim, pessoas que em sua maioria, foram e ainda são lideranças do bairro, tanto na área política, de movimentos sociais e ONGs, como da área da música ou religião, todos ligados ao processo de ocupação e construção de algumas bases da comunidade.

Durante os contatos e entrevistas interagia, auxiliando com informações e com questões relativas a processos relevantes para a formação da comunidade, ou mesmo instigando estas pessoas a narrar acontecimentos e seus papéis sociais, já que muitas vezes, participou de projetos sociais, dos mais variados campos, junto a estas pessoas.

Assim, me levando a diversos locais do bairro, seja a Restinga Velha ou a Nova, me apresentando a pessoas, auxiliou para que as portas e universos de cada morador entrevistado fossem para mim abertas.

\section{Glória}

Glória foi uma destas pessoas com quem tive contato através de Coutinho. Moradora da Restinga Velha tem 60 anos e é dona de uma flora, uma casa de produtos para religião afro-brasileira.

Tem grande envolvimento político na comunidade, participou da formação da Polícia Comunitária, de uma unidade da FEBEN (Fundação Estadual do Bem - Estar do Menor), atual FASE (Fundação de Apoio Sócio - Educativo do Estado do Rio Grande do Sul) que lá foi estabelecida. 


\section{Maria Clara}

Maria Clara foi outra informante a qual fui apresentada, tem 58 anos e é moradora da Restinga Velha. Casada com seu Ênio, trabalha como supervisora de uma cooperativa de garis que atuam em Porto Alegre. Maria Clara também tem sua trajetória relacionada à participação em movimentos sociais e culturais. Esteve presente na formação do primeiro Clube de Mães do bairro, além de ter participado de um grupo de mulheres negras e da diretoria da Escola de Samba Estado Maior da Restinga.

Tive contato por duas vezes com Maria Clara, em sua casa na Restinga Velha. Na primeira vez que realizei entrevista, Maria Clara se colocou em uma posição de narradora, se arrumou, passou batom, colocou roupas e falou bastante. Passou-me alguns recortes de jornais com suas fotos e mesmo um livro Memória nos bairros da Restinga.

$\mathrm{Na}$ segunda visita Maria Clara, me convidou para almoçar na sua casa, a auxiliei no preparo do almoço e nesta ocasião seus três filhos, marido seu Ênio, e seus netos estavam presentes.

\section{Boréu}

Walter Calixto Ferreira, o Boréu, nesta rede de certa forma representa um líder religioso e étnico. Africanólogo e tamboreiro representa a comunidade da Restinga e a própria etnia e religião em outros locais da cidade, do país e até internacionalmente.

Antes de conhecer pessoalmente Boréu eu já havia ouvido falar dele, pela questão da religião afro-brasileira e pela sua militância relacionada à etnia. Quando Coutinho pensava em quem poderia me auxiliar na pesquisa citou Boréu, dizendo ter uma grande amizade com ele. No primeiro dia que me levou até a casa de Boréu, não conseguimos ter contato com ele, pois, ele estava dando uma entrevista para alunos de uma faculdade.

Na segunda vez que fomos até lá, era por volta das $16 \mathrm{~h}$ e não o encontramos em casa, Coutinho disse que provavelmente ele estaria no bar em frente a sua casa e foi lá que o encontramos. Um senhor franzino, de óculos, com um anel com uma pedra vermelha no dedo mindinho, sentado em uma mesa de bar, com três garrafas de cerveja. Quando viu Coutinho reclamou de sua ausência, Coutinho respondeu que era ele que estava viajando muito, ele disse que realmente havia estado no Uruguai e na Argentina nos últimos dias. Coutinho me apresentou a ele, dizendo que eu era uma estudante de antropologia que queria fazer um trabalho sobre a origem do bairro. Boréu disse: é um trabalho difícil de fazer, já que cada um 
vai contar de uma forma. Falei que esta era riqueza de fazer um trabalho ouvindo os relatos de diferentes pessoas. Marcamos um encontro para o final de semana seguinte.

Cheguei a sua casa, e ficamos na sala, meus olhos percorriam as paredes cheias de fotos de Boréu em vários lugares do país. Troféus e estatuetas no armário de sua sala. Antes de começar a falar pediu para que eu explicasse com era a intenção da pesquisa, e ao me ver com um gravador disse que preferia que o primeiro encontro fosse mais informal, sem o uso de gravador. Segundo ele: "precisamos nos conhecer". Boréu relatou um pouco de sua trajetória iniciando pelo seu nascimento em 1924, na cidade de Rio Grande/RS, chegando a Porto Alegre com um ano e alguns meses indo morar no Arraial da Baronesa. Um conhecido reduto de negros na cidade de Porto Alegre. Boréu também morou na colônia Africana, local da cidade que se situava entre os bairros Bom Fim e Rio Branco.

Em 1954, foi morar na Restinga inicialmente morou no Barro Vermelho e atualmente mora a Restinga Nova. Segundo Boréu foi nessa época (1954) que iniciou o saneamento no Areal da Baronesa, na Ilhota, momento em que muitas famílias tiveram que sair de lá indo para outros locais da cidade como a Restinga.

Seus avós eram africanos e é um dos poucos que ainda fala yorubá o dialeto africano. Há uma polêmica segundo a sua idade, ele diz que tem 81 anos e demais pessoas da rede dizem que ele tem por volta de 90.

Boréu tem uma série de publicações ligadas à religião afro-brasileira e participou de um documentário sobre a colônia africana. Sempre que eu ia até sua casa gostava de tirar as caixas do armário mostrando seus livros e fotografias. No início se mostrava um pouco distante e irredutível, talvez um pouco frio e sem muito interesse, mas aos poucos, quando passei a freqüentar sua casa, conhecendo seus filhos e netos, bem como discutindo temas ligados a etnicidade e política Boréu passou a uma atitude de adoção para comigo. Abrindo-se muito mais para falar de suas memórias e conjuntamente para brincadeiras e piadas. Esse tom mais jocoso no qual eu também participava de suas piadas rindo, aceitando e devolvendo com mais piadas, acredito ser responsável pela aproximação e maior qualidade do vínculo.

Foi a partir do contato com Bóreu que comecei a perceber que a rede de informantes que estava se formando eram de pessoas que de certa forma eram lideranças na comunidade e que tinham grande influência sobre os demais moradores, sendo pessoas que estavam em uma posição pública com papéis sociais privilegiados na divulgação de suas idéias ou mesmo influenciando nas ações relativas a questões importantes no cotidiano da comunidade, seja 
pela militância, ou mesmo pela religião ou atividades culturais que interferem no dia-a-dia das pessoas e dos rumos da própria comunidade.

\section{Delmar}

Delmar Barbosa está vinculado a atividades culturais e sociais, pois é músico compositor, carnavalesco, poeta e um dos fundadores do Instituto Cultural Afro-Tinga.

Morador da Restinga Nova tem 55 anos, e antes de morar na restinga nasceu e morou na ilhota, também reduto de negros da capital. Foi radialista, e participou de um conjunto musical de samba, o "Café com Leite". Além de ter publicado dois livros de poesia e sua biografia.

A sua casa, é repleta de elementos que aludem a sua atividade ligada a música, em todos os cantos, da sala de entrada a segunda sala onde guarda muitos vinis, CDs e fitas de sambas que gravou, de músicos que auxiliou. Todas etiquetadas e enfileiradas. Nas paredes fotos, como locutor, com celebridades do samba ou do pagode.

Delmar, mora sozinho, já teve três esposas, tem filhos e netos. A sua casa é o local onde acontecem as reuniões para a formação da ONG Instituto Cultural Afro-tinga. Onde os participantes englobam pessoas da rede, como Coutinho e Fonseca.

Em sua casa participei de várias reuniões para a fundação do Instituto Cultural AfroTinga, do qual Delmar queria que eu participasse como secretária. Delmar e Coutinho tinham uma atitude de adoção para comigo, participando ativamente da pesquisa e cobrando e acompanhando os resultados obtidos, exemplo disso, foi a participação dos dois na assistência da apresentação da pesquisa no Salão de Iniciação Científica em Outubro de 2005. Na ocasião construí um cartaz com imagens do bairro e dos informantes com algumas considerações sobre a pesquisa, no final da apresentação pediram se poderiam levá-lo para apresentar para os demais moradores, pois segundo eles "o povo tinha que ver o que se estava falando sobre a Restinga na faculdade".

A observação participante em eventos como rituais de religião, festas de carnaval, reuniões de ONGs, instituições e órgãos públicos foi importante para conhecer aspectos da experiência destes habitantes, frente ao bairro e a cidade. Mas, grande parte da pesquisa de campo foi realizada nos ambientes familiares, nas casas dos informantes. 


\section{Configuração espacial e paisagem do bairro Restinga na cidade de Porto Alegre.}

O processo de industrialização em Porto Alegre, agravou os problemas de habitação. A mecanização da lavoura expulsou agricultores do campo que passaram a acreditar que a cidade lhes traria melhores condições de vida. A criação da C.L.T (Consolidação das Leis do Trabalho) que não contemplou os trabalhadores do campo também foi um fator que contribuiu para o êxodo rural. Os trabalhadores do campo que vinham para a capital em busca de melhores condições de vida deparavam com a indústria que requeria mão-de-obra especializada. Assim, muitas vezes, estes trabalhadores acabavam por passar por experiências de subemprego, como trabalhar como biscateiros, catador de papéis, etc. (Marion Kruse Nunes, 1990).

O êxodo rural, no período compreendido entre 1940 e 1950, representou mais de 70\% do aumento da população em Porto Alegre.

As dificuldades financeiras contribuíram para as questões da subabitação em Porto Alegre, surgindo assim, as malocas e vilas pela cidade. Foi nessa época que surgiram as vilas Dona Theodora, Ilhota e dos Marítimos, alterando a paisagem urbana, explicitando as desigualdades sociais.

A Prefeitura optou pela retirada dessa população das áreas centrais e valorizadas da cidade, realocando essa população para áreas mais afastadas, como a Restinga, situada na zona Sul da capital.

Segundo a SPM (Secretaria do Planejamento Municipal):

O núcleo urbano da Restinga originou-se na década de 60 , quando por iniciativa Poder Público, dentro de uma política de "desfavelização", foi destinada para o reassentamento de famílias de baixa renda que ocupavam áreas consideradas estratégicas para o desenvolvimento urbano no centro de Porto Alegre. Desta forma, do lado direito da via principal - Estrada João Antônio da Silveira - desenvolveu-se primeiramente a Restinga Velha, constituída de habitações unifamiliares, e do lado oposto, a partir dos anos 70, com recursos do Poder Público, construiu-se a Restinga Nova, formada por conjuntos habitacionais que vieram a abrigar famílias com mais disponibilidade de recursos. A partir dos meados da década de 70, a área passou a ser ocupada também por iniciativa de loteadores particulares, sendo hoje o maior bairro do centro-sul do município. São núcleos habitacionais na área o Barro Vermelho, Chácara do Banco, Flor da Restinga, Vila Mariana, Cabriúva, Núcleo Esperança, Monte Castelo e muitos outros, mais ou menos distantes da malha viária que consolida o núcleo mais central.

A ocupação do bairro se deu, inicialmente, pela região que hoje é chamada de Restinga Velha. Que passou a ser opção dos moradores da cidade que não tinham para onde ir. 
Em 1969, a Prefeitura planejou um núcleo habitacional, que contaria com casas, escolas, assim surgia a Restinga Nova.

\section{A Chegada ao Bairro Restinga}

Ao se aproximar da Restinga, a variação na paisagem é notável, quase na entrada do bairro, de longe, a imagem que temos se aproxima de uma região rural, com algumas montanhas verdes, muitos locais na beira da estrada com um grande lote, sem construção alguma. Em alguns, até podemos encontrar cavalos e vacas pastando, barracões que lembram uma região rural. Há asfalto até chegar a Restinga, mas fica no centro da estrada, nas laterais, há muitas vezes uma grande região de terra, de chão batido.

\section{Primeiras Impressões sobre o Bairro}

$\mathrm{Na}$ entrada do bairro, uma rótula, e nas laterais encontramos um pequeno comércio, supermercado, açougue, um pequeno centro comercial, umas bancas com verduras e frutas, e outra com roupas e demais mercadorias, como as bancas de camelôs do centro da cidade.

Há uma avenida principal, a Joaquim José Remião, pavimentada, onde à direita situase um grande conjunto habitacional, com blocos de prédios, com cerca de quatro andares, pintados de uma cor que lembra bege, mas com uma pintura degradada, ocupando uma grande quadra da rua.

De um lado, destaca-se a quantidade de prédios ligados ao poder público, quadra de basquete, pavilhões. Em seguida, muitas igrejas e órgãos de assistência social, por exemplo, o Ananda Marga, instituto indiano que presta um serviço de assistência à população da Restinga com uma escola. Destaca-se ainda, a igreja Assembléia de Deus e o Instituto Renascer da Esperança, um projeto de uma gari, Roseli, que se tornou um personagem famosa, ao ser entrevistada pelo Jô Soares na Rede Globo de Televisão; a Igreja do Sétimo Dia, um centro espírita.

Do outro lado igrejas, um centro espírita, igreja católica, e o CECORES (Centro de Comunidade da Vila Restinga). O CECORES aproveitou a estrutura dos CIENS (Centro Integrado de Educação Pública) que foram implementados, aqui no Rio Grande do Sul, pelo ex-governador Alceu Collares e atualmente é um centro cultural e de práticas esportivas, contando com quadras de futebol, de basquete, piscinas, atividades de dança. O CECORES é um grande prédio de tijolo a vista com quadras, salas e salões, na parte externa, muita grafites coloridos, parques infantis. 
Próximo ao CECORES localiza-se o terminal de ônibus do bairro que é novo, estilo clean, de concreto, aberto e com estruturas de metal, contrastando com os prédios antigos e largos de um grande conjunto habitacional de um lado e com uma paisagem natural ao fundo, com morros cobertos de verde e árvores.

Nesta mesma avenida há um grande conjunto habitacional o Monte Castelo, composto de quatro andares com blocos grandes e muito próximos cercados por uma grade em toda a sua extensão. Ao lado do conjunto, encontramos um supermercado, locadora, livraria, academia de ginástica. Essa mesma Avenida no final da tarde é um grande ponto de sociabilidades onde encontramos muitas pessoas na rua, caminhando, correndo, andando de bicicleta, ou passeando com cachorros.

A diversidade dos elementos que formam a decoração das casas e a própria construção é muito rica, algumas com muitas plantas, outras decoradas com muitas garrafas plásticas. $\mathrm{Na}$ questão da segurança das casas, podemos visualizar alternativas como colocar garrafas de vidro quebradas no murro. A maior parte casas de concreto de apenas um piso, gradeadas, mas com muitos elementos decorativos que dão identidades muito diferenciadas a cada uma delas.

A presença de animais domésticos (cachorros) é grande, talvez por medida de segurança, eles muitas vezes ficam acorrentados em frente ao pátio das casas; enquanto se passa pelas ruas, é comum ouvir o ruído de cachorros latindo. As casas também são, muitas vezes, próximas à rua.

Além da divisão entre as duas Restingas, a Nova e a Velha, existem subdivisões que são chamadas pelos moradores de unidades. Entre estas unidades há uma espécie de praça, um espaço com grama, onde não há nenhuma construção, alguns destes espaços possuem goleiras sendo espaços também destinados a jogos de futebol.

$\mathrm{Na}$ avenida principal, ampla e asfaltada, podemos avistar um canteiro central que se transformou em uma praça, de concreto, com poucas árvores plantadas em pequenos espaços destinados para elas, na grande faixa de concreto, com um monumento que parece um palco. Um prédio novo pode ser visto e destoa na paisagem de casas: é o prédio do Fórum.

O Corpo de Bombeiros, a Escola de Samba, lojas de roupas e supermercados também estão localizados nesta avenida. O interessante é que muitas lojas fecham ao meio-dia, hábito comum às cidades do interior.

A Restinga Nova é urbanizada, possui asfaltamento na rua principal, um prédio que destoa dos demais que - o prédio do Fórum, uma praça plana e larga, revestida de concreto 
com o desenho que lembra uma esplanada. Com uma feira modelo no centro funcionando aos sábados à tarde.

Quanto à sociabilidade, ela fica mais restrita à passagem, ao movimento de ida e vinda de pessoas e de acesso a estabelecimentos comerciais e de serviços.

Na Restinga Velha, onde se situam a maior parte dos moradores mais antigos, há relações de sociabilidade diferenciadas frente à Restinga Nova, onde muitas pessoas ficam em frente às casas, conversando, tomando conta das crianças que brincam na rua, visualiza-se vizinhos se visitando e pequenos bares sempre com pessoas sentadas a sua frente. Há uma maior quantidade de pessoas na rua, em sua grande maioria jovem e crianças, que se apropriam de diversas formas, crianças fecham as ruas e brincam com bolas e tacoboll, jovens sentados nas calçadas formando grupos, enquanto algumas crianças ouvem e dançam imitando coreografias das músicas. "funk" em frente suas casas.

No aspecto físico, caracteriza-se uma maior quantidade de casas de madeira, ruas de chão batido, automóveis estacionados na rua. Essa região tem um relevo mais acidentado, com morros, diferente da Nova, mais plana. E, no interior do bairro, há concentração de moradias irregulares, sem saneamento, ou calçamento.

Alguns elementos encontrados na paisagem urbana apontam para referências simbólicas culturais com os quais estes moradores convivem: exemplo disso é um pórtico que se encontra na entrada do bairro, onde de um lado há uma imagem de um orixá, de outro homens jogando capoeira, imagem aludindo ao carnaval. Sem dúvida algumas pessoas, da comunidade ou não, com maior ou menor poder de decisão influenciam nestas escolhas, mas o fato é que de alguma forma representam a imagem que se tem, ou que se procura formar sobre o bairro.

A Restinga tem, freqüentemente, sua imagem associada a um território violento, ou mesmo através de suas expressões culturais na cidade através das sociabilidades lúdicas ligadas ao carnaval, por exemplo, ao samba, a religiões afro-brasileiras ou mesmo a mobilização política e social em busca de cidadania.

Notícias de jornais se associam às imagens que o bairro tem perante a cidade. Muitas pessoas que não moram no bairro Restinga ou nunca foram até lá. Tomam conhecimento dele a partir das imagens veiculadas pelos jornais ou pela televisão. Durante o período da pesquisa, acompanhei tanto o jornal Zero Hora quanto o Diário Gaúcho, as notícias mais freqüentes estão nas páginas policiais; outras abordam o período do carnaval, ou mobilizações políticas nas quais moradores pedem a vinda de um hospital, por exemplo, ou reivindicam protesto melhorias nas condições de escolas. 
Participei dessa experiência de apenas "conhecer" o bairro a partir do que se falava sobre ele. Nos jornais, TV, no imaginário da classe média, onde ouvia pessoas próximas a mim dizendo que não era para levar celular ou dinheiro, pois a probabilidade de ser assaltada era grande. Estas visões, representações existem, mas foi surpreendente encontrar um bairro grande, diversificado, com locais onde há uma boa estrutura e outros nem tanto, ou mesmo com um cotidiano familiar, com pessoas com uma postura política diferenciada, ou mesmo valores e visões de mundo e práticas diferenciadas.

O deslocamento da região central de Porto Alegre, além de ser um deslocamento geográfico, foi um grande deslocamento epistemológico. No sentido de conhecer o outro, participar de um cotidiano diferente do meu habitual. Conhecendo diferentes estilos de vida, sociabilidade, ou seja, uma experiência urbana diferenciada, tanto no que se refere as trajetória, quanto nas próprias vivências na cidade.

\section{O estudo da cidade}

A antropologia urbana tem por objetivo compreender de que forma os fenômenos sociais são produzidos, reproduzidos e vivenciados no cotidiano dos habitantes da cidade.

Autores clássicos da sociologia da passagem do século XIX para o XX, tais como Durkheim, Weber, Tönnies e Simmel se preocuparam em estudar os fenômenos urbanos. Todos se voltaram, por caminhos distintos, à compreensão das especificidades das sociedades modernas, cujo centro de interesse foram as metrópoles industriais, com intensas mudanças no plano urbanístico, populacional (tendo em vista, um novo ciclo de desenraizamento rural) e nos modos de vida. (FRUGOLI, 2005, p. 4).

Weber (1979) em relação ao fenômeno urbano, considera a cidade, estreitamente relacionada com as características da civilização ocidental, em um período específico de seu desenvolvimento, pois foi na cidade ocidental que surgiram as principais instituições políticas e jurídicas da sociedade ocidental moderna. Para o autor, a característica essencial do assentamento urbano é a simultaneidade de funções econômicas e político-administrativas .

Na cidade do início da era moderna, o funcionamento do mercado dependia de um conjunto de leis que o regulavam. O solo urbano podia ser vendido livremente; adquirindo valor de troca, funcionava como capital. Estas condições favoreciam a livre edificação da cidade, surgindo a necessidade de que se elaborasse o direito urbano, outra inovação revolucionária deste período. 
A autonomia econômica das cidades permitia que elas ganhassem em troca, autonomia política, propiciando também a seus habitantes uma distinção jurídica pessoal, a cidadania. Surgiam, nas cidades, novas formas de solidariedade e diferentes laços familiares.

Durkheim, apesar de não ter estudado especificamente o fenômeno urbano, desenvolveu conceitos que fundamentam a idéia de cidade como uma comunidade orgânica, com divisão social do trabalho e com uma estrutura institucional baseada em crenças e costumes que formam a consciência coletiva (DURKHEIM, p. 342, 1995).

Estes autores clássicos nas Ciências Sociais influenciaram pesquisadores da Escola de Chicago, um grupo de pesquisadores que procuravam colocar o urbano como locus privilegiado para análise de mudanças sociais. Entre estes primeiros autores que trabalharam com a noção de cultura urbana, destacam-se estudiosos tais como Park (1916), que concebeu a cidade como um campo de investigações da vida social; e Wirth (1938), que leva em consideração variáveis como tamanho densidade e heterogeneidade. Temas como processos de imigração, os estudos étnicos e segregação foram abordados em seus estudos.

Park (1916, p. 29) considera que a organização física e a ordem moral influenciam-se mutuamente. Para o autor toda cidade é uma combinação de meio físico e variáveis, uma forma de habitat humano em que uma massa crescente de organismos luta para satisfazer suas necessidades elementares de sobrevivência. $\mathrm{O}$ autor é caracterizado pela sua visão da Ecologia Urbana, identificando processos de interação no meio urbano, tais como competição, conflito, adaptação e assimilação.

Com a utilização de métodos qualitativos, a Escola de Chicago desenvolveu temas como marginalidade, segregação étnica, bem como questões relacionadas a temática da complexidade das sociedades complexas.

\section{Sociedades complexas}

No Brasil, Gilberto Velho (1975) e Viveiros de Castro (1978) desenvolveram estudos a cerca das sociedades complexas, baseados nestes autores.

O estudo das sociedades complexas causou um grande deslocamento do olhar e do fazer antropológico, já que esta área de conhecimento no início de seu desenvolvimento estava habituada a estudar sociedades em pequena escala e relativamente homogêneas. $\mathrm{O}$ primeiro e grave risco metodológico é, ao isolar, por motivos de estratégia de pesquisa, segmentos ou grupos da sociedade, passar a encará-los como unidades realmente independentes. Gilberto Velho (1999) afirma: 
A noção de complexidade traz também a idéia de uma heterogeneidade cultural que deve ser entendida como a coexistência, harmoniosa ou não, de uma pluralidade de tradições cujas bases podem ser ocupacionais, étnicas, religiosas, etc. Obviamente existe uma relação entre estas duas dimensões - a divisão social do trabalho e a heterogeneidade cultural.

Aqui cabe salientar a importância do estudo sobre os diferentes grupos urbanos no meio citadino, segundo Eckert e Rocha (2000, p.5) "Não se pode esquecer aqui que toda obra humana remete a uma produção simbólica, sendo os territórios de sociabilidade de uma cidade nichos de sentidos produzidos por uma comunidade". Sendo assim, podemos afirmar que "o deslocamento dos grupos/indivíduos entre as 'províncias' e 'territórios' de significação é uma das questões cruciais para se compreender o fenômeno da memória coletiva e, por conseqüência, da estética urbana das modernas sociedades urbano-industriais".

Neste contexto urbano de sociedades complexas e suas dinâmicas culturais e sociais envolvendo diferentes grupos/indivíduos, o Bairro Restinga mostra-se um local heterogêneo no que diz respeito a sua população e territórios. Mas, com algumas especificidades envolvendo seus conjuntos de símbolos, tanto identitários, quanto étnicos. Segundo Gilberto Velho:

Em qualquer sociedade e/ou cultura é possível distinguir áreas ou domínios com um certo grau de especificidade. É importante para o antropólogo verificar como os próprios nativos, indivíduos do universo investigado, percebem e definem tais domínios para não cairmos na armadilha muito comum de impormos nossas classificações a culturas cujos critérios e crenças possam ser inteiramente diferentes dos nossos (VELHO,1999, p. 15).

Uma forma de perceber quais são as áreas ou domínio de certa cultura ou sociedade é identificar as fronteiras culturais de determinado grupo, fronteiras intimamente associadas a sua identidade.

Barth (1976), em seus estudos de etnicidade e identidade, substituiu uma concepção estática da identidade étnica, por uma concepção dinâmica. Segundo o autor:

(...) Essa identidade como qualquer outra identidade coletiva (e assim também a identidade pessoal de cada um), é construída e transformada na interação de grupos sociais através de processos de exclusão e inclusão que estabelecem limites entre tais grupos, definindo os que integram ou não. (apud. PUTIGNAT \& STREIFF-FERNAT, p. 11)

Grupos urbanos e/ou indivíduos que fazem parte das sociedades complexas, heterogênea e dinâmica, possuem trajetórias próprias no meio urbano. Como o processo de 
desenraizamento e deslocamento na cidade envolve tensões e suas diversas facetas que vão desde o deslocamento e a falta de vínculos á construção de novos laços. A memória dos habitantes da cidade faz parte das relações sociais destes com os demais indivíduos e grupos, envolvendo questões de redes sociais, sociabilidade diretamente envolvidas com a sua experiência urbana.

A partir de trajetórias sociais e experiências compartilhadas no meio urbano, podemos verificar a complexidade de elementos que se entrecruzam na formação e significados atribuídos a um território urbano. Questões sócio-econômicas, étnicas, históricas, estão imbricadas com a trajetória histórica da cidade.

\section{Projetos de vida e dificuldades iniciais}

Em relação as sociedades complexas e aos projetos que orientam escolhas, segundo Gilberto Velho (1990) coloca-se como problema a relação entre projetos individuais e os círculos sociais em que o agente se inclui ou participa. A idéia central é que, primeiramente, reconhece-se não existir um projeto individual puro. Os projetos são elaborados e construídos em função de experiências sócio-culturais, de um código, de vivências e interações interpretadas.

Ao questionar os moradores sobre o que os orientou na chegada a Restinga, inúmeras foram as respostas. Elementos religiosos ou místicos se misturavam a elementos de cunho ideológico, por exemplo.

No relato de Maria Clara, 58 anos, moradora da Restinga Velha, sobre o que havia motivado sua escolha por morar na Restinga podemos identificar aspectos por assim dizer "místicos". Relata que vivia com muitas dificuldades em Alvorada, cidade da grande Porto Alegre, com seus filhos e com outro marido e fez consulta a uma consulta com uma vidente, esta lhe falou que ela iria ir para um lugar muito bom, que no início iria ser difícil, mas que seria um bom local. para morar. Ela então se mudou para a Restinga, local onde suas primas já moravam, para segundo ela "construir uma nova vida".

Glória, que antes de morar na Restinga morava no Bairro Glória, na região centro-sul de Porto Alegre. Em relação a sua chegada ao bairro relata :

"A gente veio pra cá, eu não, que vim mais tarde, eu comecei com o trabalho comunitário."

"...assim, eu conheci a Restinga, comecei a trabalhar com crianças, aonde eu tinha algumas amigas nos trabalhos da Assembléia (Legislativa) onde eu conheci uma grande guerreira mesmo. Ela era da FEBEN e a gente 
começou a se envolver, aí nasceu a Casa Lar. Esse foi o primeiro passo que a gente deu, nós tínhamos fundado setenta e cinco Casas Mãe..."

Segundo Velho (1990) de qualquer forma, o projeto não é um fenômeno puramente interno, subjetivo. Formula-se e é elaborado dentro de um campo de possibilidades, circunscrito histórica e culturalmente, tanto em termos da própria noção de indivíduo como dos temas, prioridades e paradigmas culturais existentes.

\section{Início da Ocupação: Dificuldades e Mobilização da Comunidade}

...Bom, começando a te contar um pouquinho da história da Restinga, como foi criada a Restinga... Isso é uma coisa que nasceu dentro de um gabinete. O projeto da Restinga é o Fala Favela, é um sonho da Olga, do Arthur Zanela e do Pujol (Reginaldo). Como eles queriam desocupar alguns bairros, algumas favelas, por alagamento uma série de problemas que tinha, foi onde surgiu a Restinga e ai veio pra cá com o nome (de) Fala Favela, assim, foi feita em partes, a Restinga.

Glória, Restinga Velha

Segundo Boréu em 1954 iniciou o saneamento no Areal da Baronesa. Período em que muitos dos moradores de lá. foram removidos para a Restinga.

"Os poderes públicos foram desorganizando a população que lá morava. E os pobres sem condições não tinham outra alternativa. Não queriam que ficassem na entrada (da cidade) mas na saída. Os poderes públicos queriam o desenvolvimento, então, joga para lá.... Ficamos desarticulados, muitos não tinham conhecimento de causa, eram por volta de 10 a 15 mil pessoas, hoje aqui já são 150 mil...

O Regime Getulista dava melhores condições para a população, mas no início não tínhamos saneamento básico, não tinha esgoto, era o Cubo.

A elite que estava em desenvolvimento foi fazendo saneamento, outros lugares da cidade também sofreram com isso, eles foram empurrando a Goethe e a Colônia Africana também."

Boréu, Restinga Nova

A Restinga, além de ser distante do centro, não tinham nem sequer uma infra-estrutura básica necessária. Não tinha água e nem luz, e ônibus só em dois horários por dia. tinha umas torneiras que ficavam ali no centro e agente ia buscar a água pra tomar banho, fazer comida.

Maria Clara, Restinga Velha

Neste início de ocupação, juntamente com esta falta de condições básicas para a habitação, surge fortemente uma mobilização popular, em pequenos grupos, como clube de mães, polícia comunitária, mutirões pela vinda de uma escola para o bairro. 
Maria Clara, por exemplo, ajudou a fundar o primeiro clube de mães e posteriormente participou de outros grupos como o de mulheres negras. Glória fez parte da formação da Polícia Comunitária, juntamente com Coutinho, que naquela época era policial.

Podemos verificar um sentimento, pautado em reivindicações, desde o início da ocupação do bairro. Segundo Park (1916), todo setor da cidade assume algo do caráter e das qualidades de seus habitantes. No fluxo do tempo, cada parte da cidade tomada em separado inevitavelmente se cobre com os sentimentos peculiares a sua população. Como efeito disso, o que a princípio era simples expressão geográfica converte-se em vizinhança, isto é, uma localidade com sentimentos, tradições e uma história sua. Dentro dessa vizinhança a continuidade de processos históricos é de alguma forma mantida.

Podemos visualizar a criação de um sentimento de vizinhança ou mesmo de construção de laços, seja ele de pertença ao bairro, ou mesmo de pertença a instituições e movimentos sociais. $\mathrm{O}$ universo de pesquisa é composto por uma rede de moradores do bairro da primeira e segunda geração que participaram desse processo inicial de ocupação. Nesta rede, destaca-se que grande parte é formada por pessoas que atuam ou já atuaram em instituições sociais, políticas e culturais. Atuando em setores diversos como música, carnaval, política e religião, expressando redes de sociabilidade e pertencimento local.

\section{Memória, identidade e laços de pertença}

A partir das lembranças e da observação no cotidiano destas pessoas que moraram em outros locais da cidade, como a própria Ilhota, podemos visualizar uma série de práticas culturais e universos de significado que ainda estão presentes mesmo diante de um deslocamento geográfico. As pessoas levam consigo suas práticas, mantendo vivos alguns significados em relação à sociabilidade, por exemplo.

Em relação a suas trajetórias em Porto Alegre, Fonseca, Delmar e Boréu moravam na região da Ilhota, na Cidade Baixa. Boa parte de suas lembranças residem na infância neste local da cidade, nas pessoas que lá moravam, hoje são narradas como personagens pitorescos.

As lembranças do carnaval na Ilhota também são muito recorrentes, sobre as tribos, os Comanches, sobre como eram as casas, a sociabilidade na rua. Segundo Linch (1974, p.9), as imagens que os habitantes de uma cidade carregam consigo sobre seus lugares e territórios são fortemente embebidas de recordações e significados de suas experiências ali vividas.

Em relação a Memória, Bosi analisa Halbachws (1990) e a questão dos quadros sociais da memória: 
A mudança de visada se dá na própria formulação do objeto a ser apreendido: Halbwachs não vai estudar a memória, como tal, mas os 'quadros sociais da memória'. Nessa linha de pesquisa, as relações a serem determinadas já não ficarão adstritas ao mundo da pessoa (relação entre o corpo e o espírito, por exemplo),mas perseguirão a realidade interpessoal das instituições sociais. A memória do indivíduo depende do seu relacionamento com a família, com a classe social, com a escola, com a Igreja, com a profissão; enfim, com os grupos de convívio e os grupos de referência peculiares a esse indivíduo" (BOSI, 1979, p.17).

Também ligado à construção de laços de pertença, outra peculiaridade dos informantes e da população do próprio bairro é ser composto por uma grande população de negros.

A questão étnica aparece como relevante nos processos de construção social da cidadania, como revelam relatos de pertencimento ao Movimento Negro e ONGs com objetivos de emancipação social.

As formas lúdicas e religiosas de pertencimento também são relevantes para configurar as relações simbólicas do grupo. A pertença à escola de samba que tem seu ponto auge de expressão popular o carnaval, ou a expressiva adesão às religiões afro-brasileiras, são exemplo disto.

A etnia das pessoas vindas da Ilhota, além da origem em comum no compartilhamento de uma história coletiva de fundação de uma comunidade, laços étnicos também expressam uma identidade em processo.

Nesse sentido, Max Weber (2004, p.267) considera grupos étnicos como grupos humanos que, se fundando na semelhança de um habito exterior e dos costumes, ou de ambos a um tempo, ou em lembranças de colonização e imigrações, abrigam a crença subjetiva em uma procedência comum, de tal forma que a crença é importante para a ampliação da comunidade. Além de uma crença em comum, que acentua as fronteiras sociais e culturais do grupo.

Assim sendo, os laços de pertença podem ser percebidos através de códigos que são estabelecidos nas fronteiras sociais e culturais do grupo. No trabalho de campo, desde o inicio, se mostraram elementos e códigos que atuavam como delimitadores de fronteiras, onde eu verificava momentos do cotidiano que valorizavam o ser negro, como sua identidade maior.

Segundo Pollack (1989), a construção da identidade é um fenômeno que se produz em referência aos outros, em referência aos critérios de aceitabilidade, de admissibilidade, de credibilidade, e que se faz por meio da negociação direta com outros. Vale dizer que memória 
e identidade podem perfeitamente ser negociadas, e não são fenômenos que devam ser compreendidos como essências de uma pessoa ou de um grupo.

Sob esta perspectiva, pude perceber a complexidade e a negociação da identidade em distintos locais e momentos em que a minha própria identidade foi relativizada, em determinadas situações de diferenciação fui considerada a "branca". Quando, contudo, participei de um baile de carnaval, ou na ocasião em que fui a uma sessão de batuque, ouvi frases de que eu era uma quase negra. Momentos em que dividia e partilhava de seus códigos, me mostrava disposta a ouvir suas histórias de vida, conhecer suas visões de mundo e aprender suas práticas.

Nos relatos, a questão de ser negro é acionada, quando se fala de segregação étnica e social pelas difíceis condições, na dificuldade de conseguir trabalho, como é o caso de Maria Clara que relata que, em uma seleção para emprego em um cinema situado em um shopping de um bairro de prestígio, passou nas provas mas não foi selecionada. Contudo, o fato de ser negra e participar da escola de samba Estado Maior da Restinga - como fundadora - ou mesmo de participar de um grupo de mulheres negras e ser adepta da umbanda na própria comunidade assume um significado de coesão e de laços maiores que caracteriza como sendo da raiz.

Dentro desta complexidade, o estudo em questão pede um maior aprofundamento a partir de relatos e da vivência no cotidiano destas pessoas para procurar compreender como se costuram estas diversas variáveis, articulando as experiências e visões de mundo dos diferentes atores sociais que participam destes projetos e vivenciam cotidianamente um espaço urbano da cidade, construindo e reconstruindo suas identidades a partir de elementos emblemáticos, acionando valores, regras de exclusão e de pertencimento a partir de questões relacionadas a memória e identidade.

\section{Considerações Finais}

Conforme foi apresentado na introdução, buscou-se demonstrar ao longo deste trabalho de que forma os moradores do bairro Restinga, na cidade de Porto Alegre, vivenciaram o processo de desenraizamento e construção de laços de pertença no meio urbano. Dessa forma, através da análise dos resultados apresentados no decorrer deste trabalho, foi possível construir as seguintes considerações:

a) O bairro Restinga é uma localidade recente, sendo a sua origem de ocupação ligada a processos de realocação ocorridos na cidade. Os moradores com quem tive contato são 
oriundos de outros bairros da cidade de Porto Alegre ou da região metropolitana. A trajetória do bairro e a trajetória dos habitantes se comunicam e se constroem mutuamente.

b) A necessidade de luta por melhores condições de vida no bairro acaba por criar um sentimento maior de pertença entre os moradores. No início da ocupação, houve a formação de vários grupos e forte mobilização popular para obter melhorias nas suas condições de vida, baseadas nas benfeitorias das condições de infra-estrutura urbana. Atualmente, muitos destes grupos populares se mantêm e verifica-se o surgimento de novos grupos, onde há uma grande adesão a estes, por parte dos moradores. Conta-se também com fortes lideranças comunitárias, em diversas áreas da comunidade, como religião, política e cultura.

c) A etnia é um ponto importante para compreender as práticas culturais que fazem parte do cotidiano dos moradores do bairro. A religião e o pertencimento a escolas de samba são exemplos disso. Alguns destes elementos também foram transformados em emblemas ou referências do bairro.

d) A construção de laços de pertença está relacionada com práticas desses moradores, que chegaram e ainda hoje constroem uma comunidade com características peculiares, através de regras de exclusão e inclusão, negociando suas identidades que estão sempre em processo de construção.

\section{REFERÊNCIAS}

BARTH, Frederik - Los Grupos Étnicos y sus Fronteras. La organización social de las diferencias culturales. México, Fondo de Cultura Económica, 1976.

BOSI, Ecléa. Memória E Sociedade: Lembranças De Velhos. Companhia das Letras, São Paulo, 1995.

DELEUZE, G. \& GUATTARI, F., 1992. O que é filosofia? Rio de Janeiro: Ed. 34.

DURKHEIM, Émile. Da divisão do trabalho social. São Paulo, Martins Fontes, 1995.

ECKERT, Cornelia; ROCHA, Ana Luiza Carvalho da. Premissas para o estudo da memória coletiva no mundo urbano contemporâneo sob a ótica dos itinerários de grupos urbanos $e$ suas formas de sociabilidade. Porto Alegre: BIEV, PPGAS/UFRGS, 2000.

FRÚGOLI, Heitor Jr. O urbano em questão na antropologia: interfaces com a sociologia. Revista de Antropologia, v.48 n.1 São Paulo jan./jun. 2005.

GEERTZ, C. A interpretação das culturas. Rio de Janeiro, Zahar, 1973.

HALBWACHS, Maurice. A Memória Coletiva. Vértice, São Paulo, 1990.

LINCH, Kevin. La Imagen de la Ciudad. Buenos Aires: Ediciones Infinito, 1974.

MAGNANI, J. G. C. Festa no pedaço: cultura popular e lazer na cidade. São Paulo, Brasiliense. 2002

NUNES, Marion Kruse. Memória nos bairros: Restinga. 2. ed. Porto Alegre: SMC, 1990.

PARK, Robert. Sugestões para a investigação no meio urbano. In: Fenômeno Urbano. Ed. Zahar, Rio de Janeiro, 1916.

PEIRANO, Mariza G. S. Onde está a antropologia? Revista Mana, vol.3, no.2, p.67-102. Out 1997. 
POLLAK Michael. Memória e identidade social. Estudos Históricos, Rio de Janeiro, vol. 5, n. 10, 1992.

POLLAK Michael. Memória, esquecimento e silêncio. Estudos Históricos, Rio de Janeiro, vol.2, n. ${ }^{\circ}$ 3, 1989.

PUTIGNAT \& STREIFF-FERNAT. Teorias da Etnicidade. Seguido de grupos étnicos e suas Fronteiras de Fredrik Barth. UNESP 1998.

WEBER, Max. Economia e sociedade : fundamentos da sociologia compreensiva. 4. ed. Brasília: Ed. da Unb, 2004.

WEBER, Max. Conceitos e categorias da cidade. In: Otávio Guilherme Velho (org.). O Fenômeno Urbano. 4a . ed. Rio de Janeiro: Zahar,1979.

WIRTH, Louis. O Urbanismo como Modo de Vida. In: VELHO, Otávio G. (org.) O Fenômeno Urbano. Ed. Guanabara, Rio de Janeiro, 1987.

VELHO, Gilberto. Individualismo e Cultura. Rio de Janeiro: Jorge Zahar Ed., 1999.

VELHO, Gilberto. Nobres e Anjos: um estudo de tóxico e hierarquia. Tese de Doutorado apresentada no Departamento de Antropologia da Universidade de São Paulo,1975.

VELHO, G. \& VIVEIROS DE CASTRO, E. O conceito de cultura e o estudo de sociedades complexas: uma perspectiva antropológica. Artefato, Rio de Janeiro, 1 jan., CEC,1978. 